\title{
The Lifetime Earnings Premia of Different Majors: Correcting for Selection Based on Cognitive, Noncognitive, and Unobserved Factors
}

\author{
Douglas A. Webber ${ }^{*}$
}

$5-2-13$

\begin{abstract}
This paper constructs a simulation approach to estimate the lifetime returns to various college majors. I use data from the 1979 cohort of the National Longitudinal Survery of Youth and American Community Survey to estimate the parameters which form the backbone of the simulation. I address selection into both higher education and specific major categories using measures of both cognitive and noncognitive ability. Additionally, I present the lifetime premia under various assumptions regarding the magnitude of unobservable sorting.

I find substantial heterogeneity in the returns to each educational outcome, ranging from $\$ 700,000$ for Arts/Humanities majors to $\$ 1.5$ million for Science Technology Engineering or Math (STEM) graduates (each premium is relative to high school graduates with no college experience). The differentials are larger when search behavior (allowing for differential unemployment spells across majors) is taken into account.
\end{abstract}

\footnotetext{
${ }^{*}$ Temple University Department of Economics. Email: douglas.webber@temple.edu

${ }^{\dagger}$ I have greatly benefited from the advice of J. Catherine Maclean, Ron Ehrenberg, Ben Ost, Moritz Ritter, and William Stull.
} 


\section{Introduction}

With average college tuition continuing to rise at a rate roughly 3.5 percentage points faster than inflation Ehrenberg (2012), graduating high school seniors face the prospect of taking on substantial student loan debt only to be confronted with an uncertain and turbulent labor market after graduating from college. It is therefore more important than ever for students to have accurate information not just about the value of a generic college degree, but also about the relative economic returns to different majors.

Recent work has focused on the role that students' expectations play in the decision of whether to attend and what to study in college. While there is certainly a large literature devoted to estimating the college premium after controlling for unobserved ability, the results are typically focused on an economy-wide average or a point in the life-cycle estimate (e.g. age 30) rather than on the lifetime earnings premium. This is an important distinction as education-specific earnings profiles differ across age groups. I also document the importance of accounting for job search behavior (differential unemployment across majors). Finally, to the best of my knowledge the lifetime college premium (adjusting for ability sorting) has never been broken down across majors ${ }^{1}$.

I use data from the National Longitudinal Study of Youth 1979 cohort (NLSY) and the American Community Survey (ACS) to construct lifetime earnings trajectories for individuals in several different degree categories (Social Sciences, Science/Technology/Engineering/Math, Arts and Humanities, and Business), as well as those with only a high school diploma or some college experience but no 4-year degree. The trajectories are generated from a simulation approach which combines lifecycle earnings paths and degree choice (NLSY) with current degree premiums (ACS). Since there is a high degree of selection associated with both educational attainment and degree choice, I use a method employed by Taber (2001) to infer the magnitude of selection bias for each major category at all points of the life-cycle. The simulated earnings trajectories are then adjusted to account for the magnitude of self-selection. Additionally, I employ a bounding method proposed by Altonji et al. (2005) to evaluate various assumptions regarding the degree of selection of unobservable on major choice.

Taber's method for backing out the selection bias is relatively straightforward: Estimate an

\footnotetext{
${ }^{1}$ See Walker and Zhu (2011) for an excellent example of lifetime earnings decomposed by major without accounting for endogenous major choice.
} 
earnings premium (Taber considered the premium to having a college diploma using the NLSY) either unconditionally or controlling only for basic demographic characteristics. Next, estimate the premium while controlling for ability and factors which might drive selection (Test scores, mother's education, etc.). The difference between the two earnings premia is an estimate of the degree of self-selection. I make use of the often-studied Armed-Forces Qualification Test (AFQT) score from the NLSY, as well as the noncognitive ability measures including the Rotter Scale and Rosenberg Self-Esteem Score, to estimate the degree of self selection for each field of study. Furthermore, I utilize the cognitive and noncognitive ability measures to separately address several types of selection (selection into attending college, selection into major, time to completing the degree, and probability of completing the degree).

I find that accounting for selection substantially alters the expected lifetime earnings premia associated with each education group examined. I estimate significant heterogeneity in the return to various majors after accounting for observable selection through cognitive and noncognitive ability. I find that Arts/Humanities graduates receive on average $\$ 700,000$ more than high school graduates with no college experience over the course of their lifetimes holding cognitive and noncognitive ability measures constant. Social Science graduates receive an analogous premium of $\$ 1.05$ million, Business majors receive a premium of about $\$ 1.4$ million, and STEM graduates realize the largest premium of $\$ 1.5$ million. Each premium varies with the inclusion or exclusion of job search behavior, with STEM gradatues having the greatest likelihood of being employed full-time throughout an entire year. Furthermore, I find that this heterogeneity in returns persists under plausible magnitudes of unobservable selection. This work has implications in several fields, including the returns to education, major choice, and student loans.

The paper is constructed as follows. Section 2 discusses the previous literature. Section 3 describes the data used to construct the lifetime earnings trajectories. Section 4 details the empirical methodology used in the simulations. Section 5 provides a discussion of the findings and their implications, and Section 6 concludes. 


\section{Background}

Estimating the returns to education is one of the oldest and most detailed literatures in empirical economics (see Card (1999) for a review). In accordance with the nonlinear impact of years of education on earnings, many studies have focused on the returns specific to discrete units of schooling such as a high school diploma or a 4-year college degree (Averett and Burton (1996); Brewer et al. (1999); Goldin and Katz (2008); Grogger and Eide (1995); Dillon (2012) to name just a few). For an extensive review of the curriculum and college major choice literatures, see the excellent article Altonji. et al. (2012).

Much of the literature on college major choice focuses on the role of expected earnings in students' decisions. While the general consensus is that expected future earnings play a large part in major choice, a variety of different methods are used to arrive at this conclusion. Berger (1988) uses a Heckman selection framework to control for self-selection into majors and produces an estimate of the short-term expected future earnings from each degree. He uses family background characteristics as exclusion restrictions from the earnings equation. The predicted earnings from the Heckman model is then included in a conditional logit model of college choice, and is found to be a significant factor in students' decisions.

Using a dynamic discrete-choice framework, Arcidiacono (2004) finds that expected earnings play a role in major choice, although less than that found in Berger (1988). Furthermore, Arcidiacono (2004) finds evidence that the exclusions restrictions used in Berger (1988) may be invalid. In a more recent study of Duke University undergraduates, Arcidiacono et al. (2012) concludes that much of the selection into majors is due to comparative advantage (i.e. students choose the major which maximizes future earnings subject to their unique mix of skills, as in a standard Roy model framework; Roy (1951)). Montmarquette et al. (2002) find a strong impact of expected earnings upon graduation from college (which accounts for both the earnings of recent graduates and the probability of completing a given degree) in their model of major choice, which also accounts for relative major premiums and the likelihood of completing a given major.

Another branch of the college premium literature focuses on the differential returns to specific skills learned in college rather than majors. Grogger and Eide (1995) document the growing importance of math ability in explaining earnings differences, decomposing this effect into both the return 
to math ability and the change in the composition of college graduates' field of degree. Hamermesh and Donald (2008) demonstrate that holding college major constant, there are substantial returns to taking upper-division science and math courses. This work is particularly relevant to the current study, as it provides evidence of differential human capital growth across majors, and thus a clear mechanism to explain differential lifetime earnings premiums across college majors.

Robst (2007) provides evidence that there can be significant wage penalties for workers employed in fields different from their college major. This could lead to differences in the returns to college majors if there are differential shifts in the supply/demand for each major, thus forcing some majors to work in outside fields more than others.

In sum, the literature suggests that there will be differential lifetime wage premia to different degrees. However, the size of such premiua and the importance of selection is unknown. The analyses performed in this paper serve as an important complement to this growing literature on major choice and the differential returns to majors.

\section{Data}

I use two datasets used to construct the lifetime earnings trajectories in this study, the 1979 cohort of the National Longitudinal Survey of Youth (NLSY) and the American Community Survey (ACS).

The NLSY is a panel dataset which began surveying 12,686 individuals annually between 1979 and 1994 and biennially between 1994 and the present. All respondents were between the ages of 14 and 22 during the initial survey year of 1979. The NLSY is quite broad in its scope of survey questions, and has been used countless times in the economics literature. It was designed in part to track the transition from school to work, and thus is well-suited for the current study. One of the most appealing attributes of the NLSY is the availability of cognitive ability measures. The Armed Forces Qualification Test (AFQT) is a composite percentile rank of four subsections of the Armed Forces Vocational Aptitude Battery (ASVAB): word knowledge, paragraph comprehension, arithmetic reasoning, and mathematics knowledge. Given its construction, the AFQT is comparable to standard college entrance test scores. The NLSY also contains data on two commonly used measures of noncognitive ability, the Rotter Scale which gauges locus of control and the Rosenberg 
Self-Esteem Score. An individual with a high score on the Rotter Scale believes their actions have little impact on the quality of their life, and has commonly been used as a measure of noncognitive skill in the labor literature (Osborne-Groves, 2005; Heckman et al., 2006). The Rosenberg Scale represents an individual's assessment of their self-esteem or self worth. While it is less commonly used than the Rotter Scale, it is also seen as a viable measure of noncognitive abilities in the education and labor literatures (Murnane et al., 2001; Heckman et al., 2006). As discussed in Heckman et al. (2006), these variables are important components of the education selection mechanism. Since the measures of cognitive and noncognitive ability were measured only once for each individual between 1979 and 1981, I must make the assumption that the economic impact of these qualities remains relatively constant over time. Fortunately, recent research supports this assumption (Cobb-Clark and Schurer, 2013).

The ACS is a large-scale nationally representative survey which is designed to replace the decennial long-form Census. It provides data on more than 3 million individuals every year, and allows for much finer geographic identifiers than any other national survey. The appeal of using the ACS as opposed to other national surveys is twofold. First, the ACS recently began asking respondents their major field of study if they attended college. Second, the large sample sizes for even narrow age group and major category bins allows for the precise estimation of regression coefficients.

There are six educational outcomes examined in this paper: high school graduates with no college experience, some college but no four-year degree, and four-year degrees in science technology engineering or math (STEM), Business, Social Science, and Arts/Humanities. These categories are chosen to be broad enough to estimate precise differences in both the NLSY and ACS parameters. A complete accounting of each major can be found in the NLSY documentation ${ }^{2}$. Below are the NLSY major category groupings which I include in each bin for the purposes of this paper:

STEM - Biological Sciences, Computer and Information Sciences, Engineering, Health Professions, Mathematics, Physical Sciences

Business - Business and Management

Social Science - Social Sciences, Psychology

Arts and Humanities - Theology, Letters, Library Science, Fine and Applied Arts, Foreign Lan-

\footnotetext{
${ }^{2} \mathrm{http}$ // www.nlsinfo.org/content/cohorts/nlsy79/other-documentation/codebook-supplement/nlsy79attachment-4-fields-study. Access date $4 / 23 / 2013$
} 
guages, Architecture

This list is obviously not collectively exhaustive, and thus all majors not included in the above fields are categorized as "other" and included in each regression model as such. The "other" category includes majors such as military science, education ${ }^{3}$, area studies, or interdisciplinary studies. This paper does not report results for the "other" category because of the dissimilar nature of the degrees contained in that group, however it is important to include this outcome as a regressor in each model so that each of the college-level educational outcomes are collectively exhaustive.

There are several sample restrictions made for both the NLSY and ACS datasets in order to construct an appropriate sample. First, only men are included in the analysis sample, consistent with many labor market studies. This is a particularly important restriction for this study given the relatively weaker labor force attachment of women in the 1979 cohort of the NLSY and the drastic differences in major choice among women (e.g. STEM fields) relative to today. Any individuals currently enrolled in school or the military are dropped. Only individuals age 18-64 are studied. In order to construct the most relevant comparison group, individuals with less than a high school diploma or any advanced college degrees are excluded from the analyses. This exclusion may understate the value of a particular major because it removes the option value of attending graduate school (see Eide and Waehrer (1998) for a discussion of the option value of graduate school). Finally, individuals are only retained in the sample if they have positive earnings over the previous year. This condition may lead to an understatement of each college premium because it necessarily removes the long-term unemployed from the sample. However, including these individuals would introduce considerable bias into the results given that extremely weak labor force attachment is likely unobservably correlated with schooling decisions.

The final NLSY sample is comprised of 3,943 men (51,377 person-year observations), while the ACS sample covers 475,896 men. Sample weights are used in each analysis presented in this paper.

\footnotetext{
${ }^{3}$ Education was not studied as a major category in this paper because many states require some postgraduate work to be certified as a teacher long-term. Including individuals with post-graduate work would introduce a large degree of endogeneity into the estimates due to selection. Not including these individuals but still looking at education majors would produce a substantial underestimate of the returns to an education degree.
} 


\section{Empirical Model}

The key contribution of this paper is to simulate selection-corrected earnings trajectories for various college majors. This section outlines the necessary components for conducting these simulations.

\section{Magnitude of Self-Selection}

Both cognitive and noncognitive ability play a large role in the choice of college major (Heckman et al., 2006). Given the strong positive link between these factors and wages, failure to account for cognitive and noncognitive measures will lead to an overstatement of the returns to education. The NLSY's detailed set of variables provides the ideal setting to measure the magnitude of this self-selection.

Using the NLSY sample, the following regressions are estimated:

$$
y_{i j}=\alpha_{0}+\alpha_{1} \text { Age }_{i j}+\alpha_{2} \text { Black }_{i}+\alpha_{3} \text { Hisp }_{i}+\gamma E d u c_{i}+\varepsilon_{i j}
$$

$y_{i j}=\beta_{0}+\beta_{1}$ Age $_{i j}+\beta_{2}$ Black $_{i}+\beta_{3}$ Hisp $_{i}+\beta_{4} A F Q T_{i}+\beta_{5}$ MotherEd $_{i}+\beta_{6}$ Rotter $_{i}+\beta_{7}$ Rosen $_{i}+\delta E d u c_{i}+\varepsilon_{i j}$

The subscript $\mathrm{i}$ indexes individuals while $\mathrm{j}$ indexes age groupings. Thus, separate regressions are run for each of the following 6 age groups: 18-25, 26-30, 31-35, 36-40,41-45, 45+. The regressions are run separately by age grouping rather than by each individual age to more precisely estimate each coefficient. The dependent variable is the natural $\log$ of the prior year's income from wages and salary. The variable age enters linearly into each regression to account for earnings growth or decline within each age category. Since the objective of this paper is to quantify the lifetime earnings premium of obtaining a given type of college degree (in other words to get as close as possible to the value of obtaining a given degree if a high school graduate on the margin of going to college exogenously received that degree) all individuals without a high school diploma or with any postgraduate work are excluded from all analyses. As a result of these sample restrictions, having a 
high school diploma but never attending college is the omitted education category. Thus, educ is a vector of mutually exclusive and collectively exhaustive (except for the base category: high school graduates) educational outcomes. This includes indicators for college attendance but no degree, and a full compliment of college degree types (STEM, Social Sciences, Business, Arts and Humanatees, and Other). AFQT represents the percentile rank of the individual's score on the Armed Forces Qualifying Test. Rotter denotes the individual's score on the Rotter scale, a standard noncognitive ability measure which gauges locus of control. Rosen represents the individual's score on the Rosenberg Self-Estem test. Finally, MotherEd describes the education attainment of each individual's mother. These controls are meant to proxy for traditionally unobserved ability, both cognitive and noncognitive, and represent the only difference between the two equations. As previously noted, the cognitive and noncognitive ability scores were measured only once, and thus these variables are assumed to remain relatively constant over time (an assumption supported by Cobb-Clark and Schurer (2013)). Additinoally, the AFQT scores are normalized by the age at which the test was taken to account for age-related bias (Heckman et al. (2006)).

I experimented with the control variables entering into the model in various less parametric functional forms (e.g. including higher order polynomials, dummy variables for each decile, etc.). There was surprisingly little difference in the estimated education parameters across these specifications. The results presented in this paper are therefore based on the most parsimonious model where each variable enters linearly into the log earnings regressions, however other results are available upon request.

The relatively parsimonious nature of Equations (1) and (2) is intentional, and is meant to avoid controlling for factors which are outcomes of educational choice but also influence earnings. For example, industry and occupation are often outcomes of major choice, and their inclusion in the model would therefore bias the estimated major premia. Thus, only a basic set of pre-market factors are included in each model.

Taking the difference of the corresponding education coefficients from each model (i.e. $\delta_{\text {Selection }}^{S T E M, j}=$ $\left.\gamma_{S T E M, j}-\delta_{S T E M, j}\right)$ yields an estimate of the selection bias usually present when we estimate education earnings premiums. These selection biases will be used later to adjust estimated earnings premiums from the ACS, which have no suitable proxies for ability.

The use of the AFQT percentile is attractive because of its straightforward construction and 
interpretation (e.g. moving up one percentile in the ability distribution). While this measure is certainly not a perfect barometer of cognitive ability, it explains roughly ten percent of the variation in yearly income all by itself ${ }^{4}$ and is a mainstay in the education literature.

There are two other models estimated on the NLSY sample which yield information on several types of selection which can be built into the simulation model. First, an ordered logit which estimates the contribution of AFQT percentile to likelihood of attending and completing college.

$$
P\left(e d u c_{i}=k\right)=P\left(c_{k-1}<X_{i} \beta<c_{k}\right)
$$

Where education may take on three values (high school diploma without any college, some college without a degree, any college degree), $\mathrm{X}$ is a vector consisting of race, ethnicity, AFQT score, Rotter Scale, Rosenberg Self-Esteem Score, and mother's education. Each $c_{k}$ represents a cutpoint (by convention, $c_{0}=-\infty$ and $c_{k}=\infty$ ).

Second, I estimate a multinomial logit of the contribution of AFQT percentile to major choice conditional on earning a college degree.

$$
P(\text { major }=k)=\frac{e^{X \beta^{(k)}}}{\left.1+\sum_{k=1}^{5} e^{X \beta^{(k)}}\right)}
$$

Where in this case $\mathrm{k}$ varies between the 5 major choices studied (Social Sciences, Business, STEM, Arts and Humanities, and Other), $\mathrm{X}$ is a vector consisting of race, ethnicity, AFQT score, Rotter Scale, Rosenberg Self-Esteem Score, and mother's education. As in all multinomial logit estimations, the coefficients for one outcome (in this case Other) are normalized to zero.

The results from these two models are used in the earnings simulation to determine the level and major (if the individual is assigned to be a college graduate) of each individual.

\section{Unadjusted earnings paths}

Using the 2011 ACS, Equation (5) is run for each of 9 age groups (18-25, 26-30, 31-35, 36-40, 41-45, 46-50, 51-55, 56-60, 61-64).

\footnotetext{
${ }^{4}$ Author's calculation based on regression sample used for this paper.
} 


$$
y_{i j}=\check{\beta}_{0}+\check{\beta}_{1}^{(j)} \text { age }_{i j}+\check{\beta}_{2} \text { Black } k_{i}+\check{\beta}_{3} \text { Hispanic } c_{i}+\check{\delta} e d u c_{i}+\varepsilon_{i j}
$$

Where the dependent variable is the natural $\log$ of prior year earnings, and all independent variables are defined ias described above. The coefficient on each education category within each age grouping, as well as the variance of residual log earnings, $\sigma_{\text {educ, } j}^{2}$, for each education category and age grouping are saved. Additionally, I save the mean and variance of log wages for workers with only a high school diploma to use as a baseline to compare the major premias.

\section{Life-Cycle Earnings Simulation}

Normal cumulative distribution functions (CDFs) are generated for each educational outcome (High school graduate w/o any college, some college w/o degree, and each major type) and age grouping based on the coefficients from Equation (5) and the variance of the residuals from each group.

Finally, a dataset is populated with 100,000 simulated workers who are randomly assigned an ability level (1-100) and two uniform random shocks (one to go with the ordered logit and one for the multinomial logit).

An individual is assigned a schooling level (high school some college, or college degree) based on the parameters estimated from the conditional logit as well as the ability and the first random shock values. Those with conditional logit scores in percentiles $64-100$ of the distribution are assigned to have completed their degree in 4 years, 54-64 in 5 years, and $44-54$ in 6 years. These numbers were chosen to match recent four, five, and six-year graduation rates from U.S. four-year institutions (IPEDS).

For those assigned to be college graduates, the coefficients on AFQT from the multinomial logit run on the NLSY sample are used in conjunction with the other random shock to assign a major to each graduate.

Log earnings are then simulated for each year of labor force participation (18-64 for high school graduates, 20-64 for those with some college, and between 22-64 and 24-64 for those with a college degree depending on the ordered logit score) based on the following equation: 


$$
\hat{y}_{i t}=\bar{y}_{j}^{H S}+\check{\delta}_{j}^{e d u c}-\delta_{\text {Selection }}^{e d u c, j}+\breve{\beta}_{a g e}^{(j)}\left(t-a \bar{g} e_{j}\right)+\breve{\beta}_{A F Q T}^{(j)}(\text { ability }-50)+f^{-1}\left(\sigma_{\text {educ,j }}^{2}\right) \forall t \in j
$$

Equation (6) describes the simulated $\log$ earnings for individual $i$ at each age $t$. The first term on the right hand side is the average log earnings of high school graduates with no college

enrollment in age group $\mathrm{j}$. The second term, $\check{\delta}_{j}^{\text {educ}}$, represents the estimated premium from the ACS for each educational category other than high school graduates (some college, and each of the major categories) in age group j. $\delta_{\text {Selection }}^{\text {educ,j }}$ represents the magnitude of selection for each educational category in age group $\mathrm{j}$ as estimated via the NLSY. The fourth term adjusts the simulated earnings for age differences within each age group $\mathrm{j}$. This simply accounts for the fact that there are returns (positive or negative) to age/experience within small age groupings without the loss of precision associated with estimating age effects for every age. The next term creates dispersion based on the assigned ability score and the estimated coefficient on AFQT from each age-group specific regression on the NLSY sample. The final term, the inverse normal CDF for each educational category and age grouping, generates dispersion in the simulated log earnings distribution based on the observed residual variation from the ACS sample. Since the NLSY has very few respondents over the age of 50, the selection parameters for the oldest age group are estimated on a pooled sample of all observations age 45 and up. This set of parameters is then applied to each of the four oldest ACS age groups.

\section{Results}

Basic information on the composition of both the NLSY and ACS samples is given in Table 1. The fraction of males with some postsecondary education experience is noticeably higher in the more recent ACS sample as compared to the 1979 cohort studied in the NLSY. This underscores the previously mentioned point that selection into higher education has likely declined over the past several decades, and therefore the results presented in this paper represent conservative estimates of the lifetime earnings premia. Additionally, note that the age distributions are quite different 
between the two samples. This is due to the relatively younger age of the NLSY cohort, and the fact that individuals were surveyed more frequently when they were younger (prior to 1994).

Table 2 presents the selection estimates for each major and age grouping as well as the coefficient on AFQT in each age grouping derived from the NLSY. This table also displays estimates of the potential bias from unobservable selection into each education category. These estimates are derived from the procedure detailed in Altonji et al. (2005), and make the assumption that the degree of selection into each education category based on observable characteristics (race/ethnicity, AFQT, noncognitive ability, etc.) is equal to the degree of selection based on unobservable characteristics.

Each of the unobservable bound estimates can be interpreted as the proportion of the estimated education premium which is due to selection rather than causation if selection on observables is equivalent in magnitude to selection on unobservables. While this assumption is inherently arbitrary, Altonji et al. (2005) argue that in most cases selection on observables is likely to exceed unobservable selection. In either case, the simulations conducted for this paper illustrate a number of different potential assumptions regarding selection and endogeneity, and the reader may decide which estimate they trust the most. It is important to note that selection on observables refers to all variables in the NLSY regressions (age, race, ethnicity, AFQT, mother's education, Rotter score, Rosenberg Self-Esteem Scale), not just the ability measures. Standard errors for each selection parameter (observed and unobserved) are estimated by bootstrapping the generation of each parameter.

Table 3 displays the estimated ACS parameters which are used as the basis for the simulation. The first row presents the average logged annual earnings for men with only a high school diploma and no college experience. The next five rows show the estimated premiums associated with each education outcome from age-group specific (5-year groupings) regressions which include only age, race, and ethnicity controls. The next row presents the coefficient on the age variable from each regression. The final six rows show the standard deviation of the logged earnings residuals of individuals in each education group. These values are used to construct the CDF for each educationby-age group, and thus generate dispersion in each simulation.

The first round of simulations are described in Table 4. This table presents lifetime earnings estimates for each education category based on Equation (6). Since the parameters are estimated based upon earnings from the previous year as opposed to wages, these numbers implicitly take 
account of search behavior and unemployment spells. This is an important point, because the probability of full-time, continuous employment varies greatly by major. For instance, proportion of STEM graduates who are employed for the entire year at a full-time job is $76.8 \%$. The corresponding proportions for Business, Social Science, and Arts/Humanitee graduates are $76.2 \%, 69.3 \%$, and $65.4 \%$ respectively.

The values in the first row can thus be taken as estimates of observed lifetime earnings for each educational outcome, comprised of both causal impact and endogenous selection. There is substantial heterogeneity in this measure of lifetime earnings, ranging from a lifetime premium of about $\$ 1.15$ million for Arts and Humanities majors to STEM majors, who have the largest lifetime earnings making roughly $\$ 2.2$ million more than high school graduates without any college experience.

The second row presents simulations which correct for observed measures of ability (AFQT, mother's education, Rotter score, Rosenberg Self-Esteem Scale) which may influence selection into higher education. As discussed in the empirical model section, the degree of selection based on these variables is estimated in the NLSY, and then applied to current earnings data from the ACS. This technique makes the assumption that selection into higher education based on observed ability has remained constant over the past 25-30 years (roughly the time period in which the NLSY cohort was making their postsecondary education decisions). I argue that this is not a restrictive assumption for the purposes of this paper for two reasons. First, since the NLSY cohort is between their mid 40's and early 50's during the 2011 ACS, the selection parameters estimated on the NLSY cohort for these age groups are precisely the parameters we would estimate if the ACS had information on respondents' standardized test scores. Second, Dillon (2012) points out that the trend in higher education has been toward students with lower grades and test scores attending college, and thus any selection correction applied to older cohorts is likely to be an overestimate for more recent cohorts (and thus the premia will be underestimated). Given that there are certainly unobservable factors (the magnitude of which will be discussed later) other than traditional cognitive ability positively correlated with both education and wages, a small overestimation of selection based on test scores simply cuts into selection based on observed factors.

After the observable selection correction is applied, the lifetime college premium ranges from $\$ 700,000$ for an Arts and Humanities major to about $\$ 1.5$ million for a STEM major. These estimates 
can be interpreted as the premia associated with each educational outcome after holding cognitive ability constant. There is however substantial variation within the field of degree categories used in this paper. Consider Social Sciences, which has a selection corrected lifetime earnings premium of about $\$ 1.05$ million. An economics major is expected to have a premium of $\$ 1.7$ million while a psychology major only receives a lifetime benefit of $\$ 700,000^{5}$. The results are not generally broken down into individual majors because of a substantial loss in precision of estimating the ACS and in particular the NLSY parameters.

The third row of Table 4 displays the present discounted value (assuming a discount factor of .98) of lifetime earnings for each educational outcome. The fourth row subtracts off average tuition faced by each group (assuming that tuition is $\$ 20,000$ per year of college attended, roughly the current national average of 4-year institutions). Finally, the fifth row reports the percent of each group which falls below the average lifetime earnings of a high school graduate without any college experience. This value ranges from a low of $3.6 \%$ among STEM majors to a high of $25.1 \%$ among those who majored in the Arts or Humanities.

Figure 1 plots the earnings trajectories for each educational outcome without any selection correction. As with the first row of Table 4, these paths can be interpreted as what we actually observe in the economy. Figure 2 plots the earnings trajectories after the observable selection correction has been applied (second row of Table 4). These lines correspond to the potential paths of a hypothetical individual with average ability. Cumulative earnings trajectories (subtracting off average tuition incurred) which account for the observable selection correction are plotted in Figure 3.

Table 5 repeats the simulations from Table 4 , but under the condition that each NLSY and ACS parameter is estimated only for workers who report working at least 35 hours per week and at least 50 weeks the previous year. Thus, these values ignore any earnings differences across majors due to search behavior (e.g. workers in certain industries may be more likely to be unemployed than others).

Comparing rows between Tables 4 and 5 provides some insight into how much of the education premium is due to increased wages and how much can be attributed to a reduction in the probability

\footnotetext{
${ }^{5}$ These estimates were computed using the social science selection correction computed in the NLSY, not economics and psychology specific corrections. The sample sizes of these majors is too small in the NLSY to obtain precise estimates of selection.
} 
of unemployment. Introducing the element of unemployment reduces the lifetime earnings of high school graduates by 14.6 percent ( $\$ 1.73$ million to $\$ 1.51$ million). The premium associated with some college experience but no four year degree is reduced by 11.6 percent $(\$ 2.02$ million to $\$ 1.81$ million). Unsurprisingly, there are differential returns to job search penalties among college major categories. The Arts and Humanities premium falls 14.5 percent ( $\$ 2.52$ million to $\$ 2.20$ million), Social Sciences drops 10.9 percent ( $\$ 2.84$ million to $\$ 2.56$ million), Business declines 7.9 percent ( $\$ 3.13$ million to $\$ 2.90$ million), and the STEM premium is lowered by 7.6 percent $(\$ 3.25$ million to $\$ 3.02$ million).

As mentioned above, the observable measures meant to control for selection into each educational group likely only capture part of the total selection effect. Factors such as an individual's self-motivation, propensity to work hard, or simple Roy model comparative advantage are only partially captured by the measures I am able to correct for (age, race, ethnicity, AFQT, mother's education, Rotter score, and Rosenberg Self-Esteem Scale). While these other selection mechanisms are inherently unobservable, and thus by definition I cannot account for them directly in the simulation model, a technique pioneered by Altonji et al. (2005) allows me to account for unobservable selection under assumptions of the correlation between observable and unobservable selection into higher education.

Altonji et al. (2005) argue that the degree of selection based on unobservables is likely to be less than that based on observable characteristics in part because the observable factors chosen for a regression model are not randomly selected (Altonji et al. (2005) show that in the case of randomly selected observables then the two types of selection will then be equal). Given the very strong link between the factors in the NLSY regressions and earnings/educational choices, it seems unlikely that the degree of unobservable selection approaches the magnitude of observable selection.

Table 6 presents simulated lifetime earnings under various assumptions about the degree of unobservable selection relative to observable selection. The first two rows are reproduced from Table 4 for comparison. Even assuming that unobservable selection is half the magnitude of observable selection yields sizable heterogeneity in the returns to the major field of degree, ranging from a premium to arts/humanities majors of $\$ 0.5$ million to business majors of about $\$ 0.75$ million, this scenario is shown in Figure 4.

Furthermore, the seventh row of Table 6 indicates that if the relative selection magnitude is 
assumed to be $90 \%$ then there is virtually no premium, signaling or human capital, to earning a college degree as opposed to just attending college at all. This would also seem to suggest that the true degree of unobservable sorting is likely far less than sorting on observables.

Finally, Table 7 presents some data regarding the distribution of lifetime earnings within each education category. This provides an important context to the previous tables since median earnings premia are only applicable to a small portion of the labor force. Median lifetime earnings are presented for each quintile of the ability distribution (as measured by AFQT score) after adjusting for the observed selection factor. The difference between majors are quite stark, with the average individual in the fourth ability quintile (60th-80th percentiles) with an arts/humanities degree making as much as a STEM or business major from the lowest ability quintile or a social sciences major in the second quintile.

\section{Conclusion}

This paper seeks to examine the relative returns to various college degrees. While few would argue that a particular major should be chosen purely based on economic returns, the underperforming labor market and increasing tuition necessitates it be at least considered by college underclassmen trying to decide their career path. This study provides some of the first evidence on the large disparities in lifetime earnings (corrected for selection) between college majors.

I design a simulation methodology which uses data from the 1979 cohort of the National Longitudinal Survey of Youth (NLSY) and the American Community Survey (ACS) to generate lifetime earnings histories for 6 education groupings (high school with no college experience, some college but no 4-year degree, and 4-year degrees in STEM, Business, Social Sciences, or Arts/Humanities).

I correct for selection into higher education and major based on cognitive and noncognitive ability using the method suggested by Taber (2001). I also present simulations which account for sorting based on unobservable factors under a variety of assumptions. This paper is the first to document the large disparities in lifetime earnings between major categories even after addressing selection bias.

I find, unsurprisingly, that various forms of selection play a substantial role in sorting into college 
and across majors. After correcting for selection, STEM and business majors received the largest premia, followed by social science, and arts/humanities majors receiving the lowest lifetime earnings boost. The results are robust to estimating the simulation parameters only from full-time employed workers, but are strongest when search behavior is taken into account.

While this paper focuses exclusively on the monetary returns to various majors, this is not meant to suggest that economic returns should be the sole or even primary determinant of major choice. If one was able to measure the utility differentials across majors the gaps may be smaller than the monetary gaps documented in this study. However, given the struggling labor market and the skyrocketing cost of higher education, economic returns must be part of the equation.

The results presented here have applications beyond the returns to education and major choice literatures. For example, there are direct applications to the optimal pricing (from the lender's perspective) and the ability/length of time to repay (from the lendee's perspective) student loans.

\section{References}

J. Altonji, T. Elder, and C. Taber, "Selection on observed and unobserved variables: Assessing the effectiveness of catholic schools," Journal of Political Economy, vol. 113(1), pp. 151-184, 2005.

J. Altonji., E. Blom, and C. Meghir, "Heterogeneity in human capital investments: High school curriculum, college major, and careers," Annual Review of Economics, vol. 4, pp. 185-223, 2012.

P. Arcidiacono, "Ability sorting and the return to college major," Journal of Econometrics, vol. 121(1-2), pp. 343-375, 2004.

P. Arcidiacono, V. Hotz, and S. Kang, "College major choice using elicited measures of expectations and counterfactuals," Journal of Econometrics, vol. 166(1), pp. 3-16, 2012.

S. Averett and M. Burton, "College attendance and the college wage premium: Differences by gender," Economics of Education Review, vol. 15(1), pp. 37-49, 1996.

M. Berger, "Predicted future earnings and choice of college major," Industrial and Labor Relations Review, vol. 41(3), pp. 418-29, 1988.

D. Brewer, E. Eide, and R. Ehrenberg, "Does it pay to attend an elite private college? cross-cohort evidence on the effects of college type on earnings," Journal of Human Resources, vol. 34(1), pp. 104-123, 1999.

D. Card, The Causal Effect of Education on Earnings, ser. Handbook of Labor Economics. Elsevier, 1999, vol. 3, ch. 30, pp. 1801-1863.

D. Cobb-Clark and S. Schurer, "Two economists musings on the stability of locus of control," 2013, forthcoming, Economic Journal. 
Dillon, "The college earnings premium and changes in college enrollment," 2012, manuscript.

R. Ehrenberg, "American higher education in transition," Journal of Economic Perspectives, vol. 26(1), pp. 193-216, 2012.

E. Eide and G. Waehrer, "The role of the option value of college atteattend in college major choice," Economics of Education Review, vol. 17(1), pp. 73-82, 1998.

C. Goldin and L. Katz, The Race between Education and Technology. Cambridge, MA: Harvard University Press, 2008.

J. Grogger and E. Eide, "Changes in college skills and the rise in the college wage premium," Journal of Human Resources, vol. 30(2), pp. 280-310, 1995.

D. Hamermesh and S. Donald, "The effect of college curriculum on earnings: An affinity identifier for non-ignorable non-response bias," Journal of Econometrics, vol. 144(2), pp. 479-491, 2008.

J. Heckman, J. Stixrud, and S. Urzua, "The effects of cognitive and noncognitive abilities on labor market outcomes and social behavior," Journal of Labor Economics, vol. 24(3), pp. 411-482, 2006.

C. Montmarquette, K. Cannings, and S. Mahseredjian, "How do young people choose college majors," Economics of Education Review, vol. 21(6), pp. 543-556, 2002.

R. Murnane, R. . Willett, M. Braatz, and Y. Duhaldeborde, "Do different dimensions of male high school students' skills predict labor market success a decade later? evidence from the nlsy," Economics of Education Review, vol. 20(4), pp. 311-320, 2001.

M. Osborne-Groves, "How important is your personality? labor market returns to personality for women in the us and uk," Journal of Economic Psychology, vol. 26(6), pp. 827-841, 2005.

J. Robst, "Education and job search: The relatedness of college major and work," Economics of Education Review, vol. 26(4), pp. 397-407, 2007.

A. Roy, "Some thoughts on the distribution of earnings," Oxford Economic Papers, vol. 3, pp. $135-146,1951$.

C. Taber, "The rising college premium in the eighties: Return to college or return to unobserved ability," Review of Economic Studies, vol. 68(3), pp. 665-691, 2001.

I. Walker and Y. Zhu, "Differences by degree: Evidence of the net financial rates of return to undergraunder study for england and wales," Economics of Education Review, vol. 30(6), pp. $1177-1186,2011$. 
Figure 1: Simulated Earnings Paths by Education Outcome: Without Selection Correction

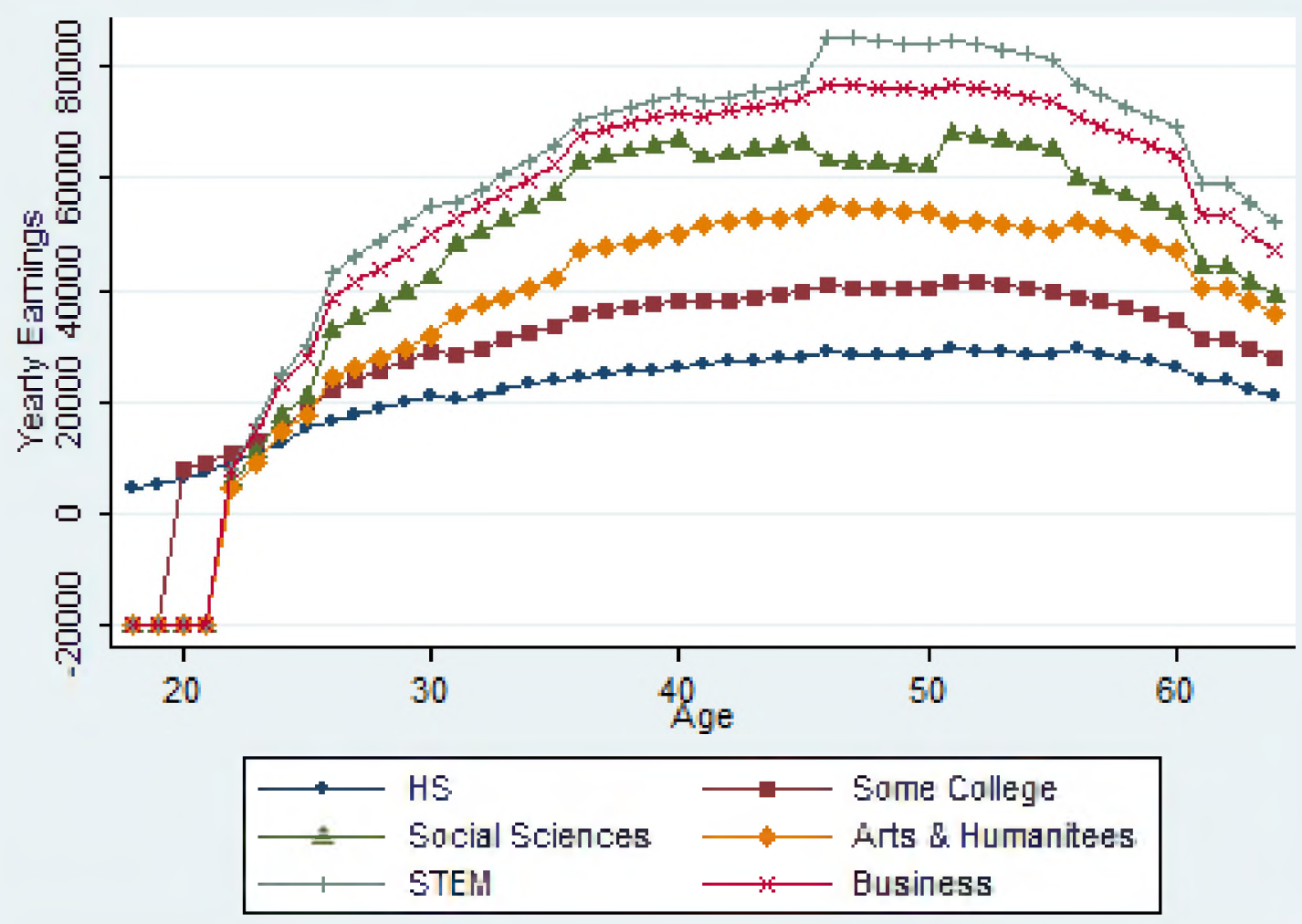


Figure 2: Simulated Earnings Paths by Education Outcome: With Observable Selection Correction

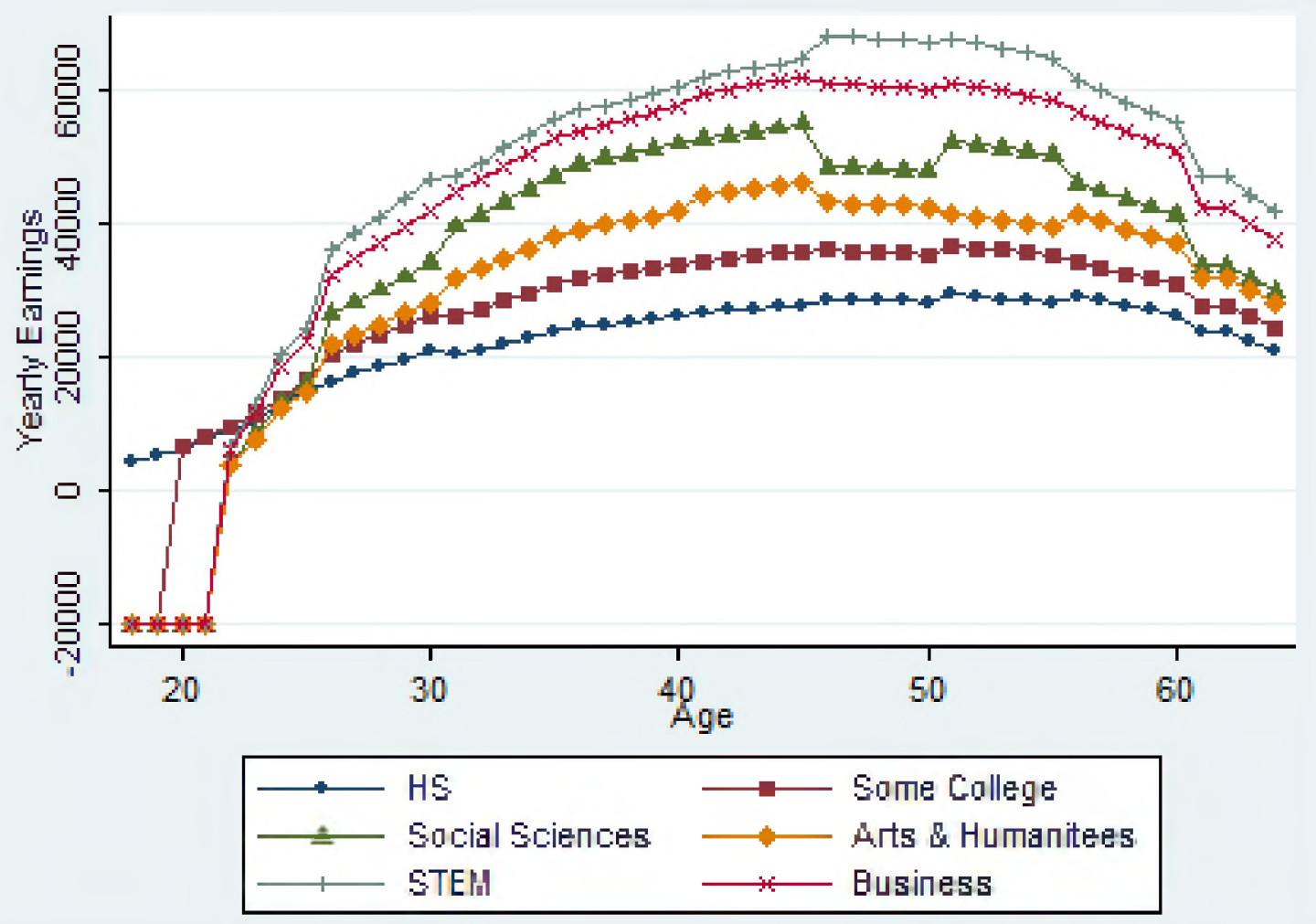


Figure 3:Cumulative Earnings Paths Minus Average Tuition by Education Outcome

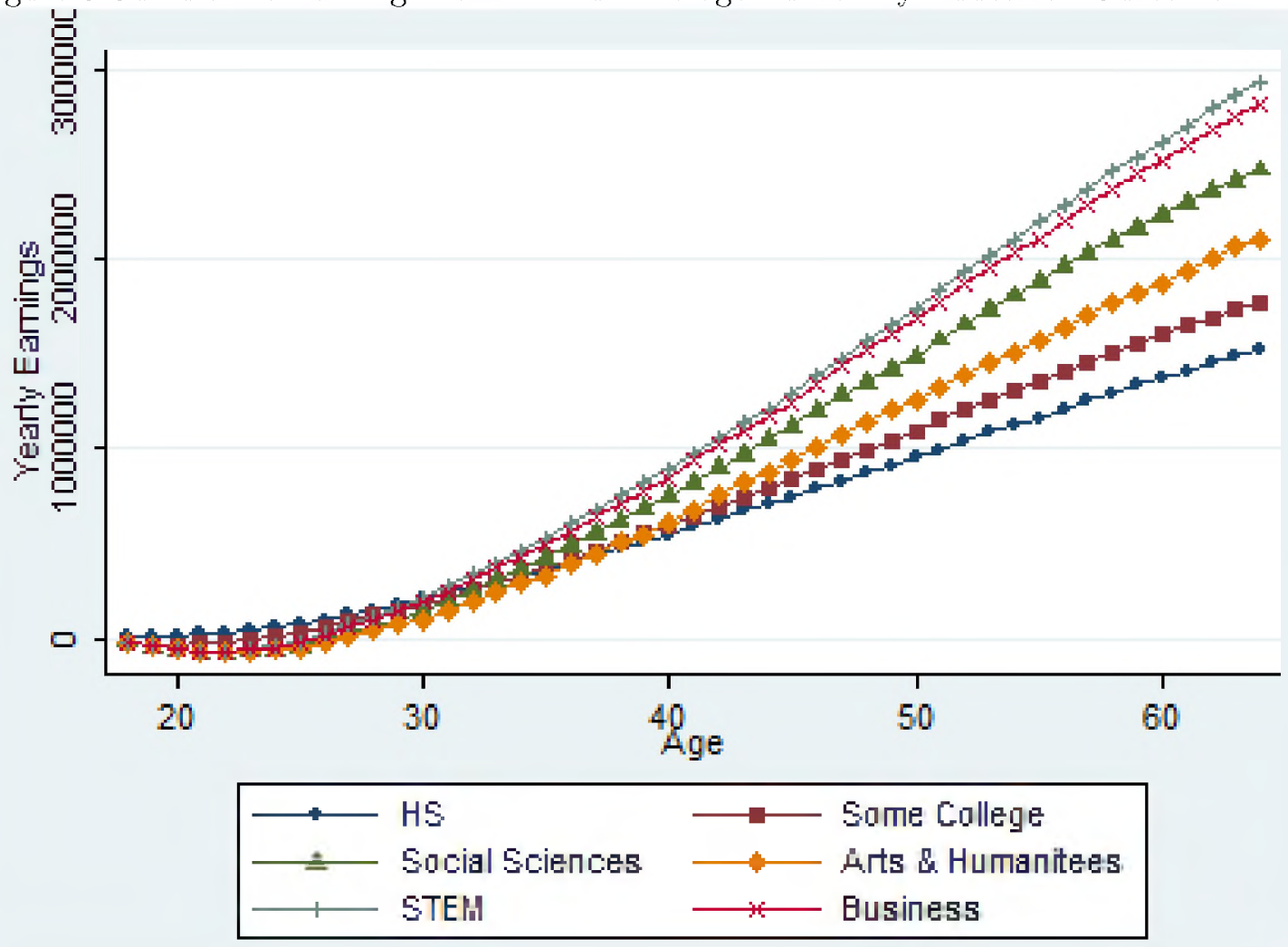


Figure 4: Simulated Earnings Paths by Education Outcome: With Observable and Unobservable (Correlation $=.50)$ Selection Corrections

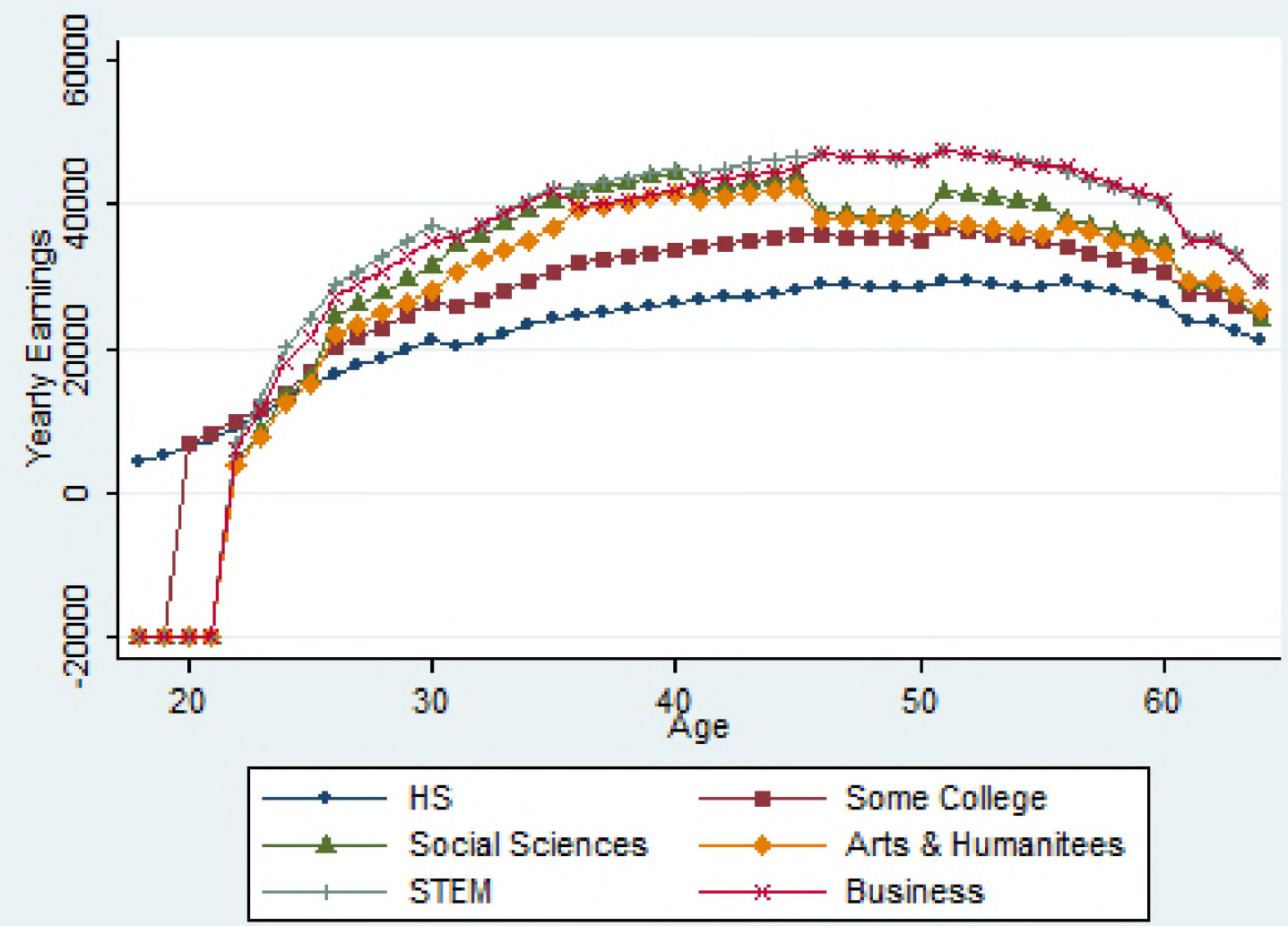


Table 1

Summary Statistics

\begin{tabular}{lcc}
\hline \hline & NLSY & ACS \\
\hline Black & .121 & .089 \\
Hispanic & .054 & .109 \\
High School & .570 & .387 \\
Some Sollege & .254 & .366 \\
STEM & .055 & .072 \\
Business & .056 & .072 \\
Social Sciences & .014 & .025 \\
Arts and Humanities & .013 & .031 \\
Age 18-25 & .189 & .114 \\
Age 26-30 & .213 & .107 \\
Age 31-35 & .182 & .105 \\
Age 36-40 & .127 & .110 \\
Age 41-45 & .125 & .118 \\
Age 46-50 & .122 & .137 \\
Age 51-55 & .008 & .136 \\
Age 56-60 & 0 & .133 \\
Age 61-64 & 0 & .061 \\
AFQT & 49.8 & \\
Rotter & 8.45 & 475,896 \\
Rosenberg & 22.8 & \\
Observations & 51,377 & \\
\hline Each 0f the NISY & 250 &
\end{tabular}

Each of the NLSY and ACS samples are comprised of men between the ages of 18 and 64 . Only individuals who have at least a high school diploma but no postgraduate work are retained in the sample. Individuals who are currently enrolled in college or the military are excluded. 
Table 2

Estimated NLSY79 Parameters

\begin{tabular}{|c|c|c|c|c|c|c|}
\hline & \multicolumn{6}{|c|}{ Age Group } \\
\hline & $18-25$ & $26-30$ & $31-35$ & $36-40$ & $41-45$ & $46+$ \\
\hline \multirow[t]{2}{*}{$\delta_{\text {Selection }}^{S T E M}$} & -.2024 & -.1733 & -.1689 & -.2128 & -.1735 & -.2236 \\
\hline & $(.0189)$ & $(.0168)$ & $(.0197)$ & $(.0233)$ & $(.0202)$ & $(.0231)$ \\
\hline \multirow{2}{*}{$\delta_{\text {Selection }}^{\text {Business }}$} & -.2307 & -.1731 & -.1666 & -.2236 & -.1792 & -.2289 \\
\hline & $(.0200)$ & $(.0155)$ & $(.0182)$ & $(.0238)$ & $(.0195)$ & $(.0223)$ \\
\hline \multirow{2}{*}{$\delta_{\text {Selection }}^{\text {Social }}$} & -.2619 & -.2089 & -.1950 & -.2490 & -.1889 & -.2625 \\
\hline & $(.0253)$ & $(.0207)$ & $(.0233)$ & $(.0288)$ & $(.0241)$ & $(.0294)$ \\
\hline \multirow{2}{*}{$\delta_{\text {Selection }}^{\text {Arts\&Hum }}$} & -.1747 & -.1145 & -.1072 & -.1817 & -.1490 & -.2368 \\
\hline & $(.0280)$ & $(.0192)$ & $(.0204)$ & $(.0246)$ & $(.0262)$ & $(.0309)$ \\
\hline \multirow{2}{*}{$\delta_{\text {Selection }}^{\text {SomeCol }}$} & -.1105 & -.0901 & -.0896 & -.1126 & -.0942 & -.1218 \\
\hline & $(.0094)$ & $(.0082)$ & $(.0103)$ & $(.0119)$ & $(.0108)$ & $(.0127)$ \\
\hline \multirow[t]{2}{*}{$\beta_{A F Q T}$} & .0045 & .0033 & .0030 & .0047 & .0035 & .0056 \\
\hline & $(.0005)$ & $(.0004)$ & $(.0005)$ & $(.0006)$ & $(.0006)$ & $(.0007)$ \\
\hline \multicolumn{7}{|c|}{ Unobservable Bounding Estimates } \\
\hline \multirow[t]{2}{*}{ STEM } & .0139 & .5436 & .6138 & .6765 & .7533 & .8417 \\
\hline & $(.0875)$ & $(.0342)$ & $(.0414)$ & $(.0499)$ & $(.0467)$ & $(.0635)$ \\
\hline \multirow[t]{2}{*}{ Business } & .1804 & .4972 & .5406 & .7336 & .7459 & .6581 \\
\hline & $(.0643)$ & $(.0302)$ & $(.0398)$ & $(.0554)$ & $(.0558)$ & $(.0722)$ \\
\hline \multirow[t]{2}{*}{ Social } & -.0169 & .2856 & .3975 & .4030 & .5906 & .6757 \\
\hline & $(.1332)$ & $(.0714)$ & $(.0859)$ & $(.0965)$ & $(.1136)$ & $(.1252)$ \\
\hline \multirow[t]{2}{*}{ Arts\&Hum } & -.3251 & .0431 & .1799 & .0234 & .3297 & .5026 \\
\hline & $(.1354)$ & $(.1001)$ & $(.0658)$ & $(.1559)$ & $(.0944)$ & $(.1034)$ \\
\hline \multirow{2}{*}{$\begin{array}{l}\text { Some } \\
\text { College }\end{array}$} & .0878 & .0666 & .0888 & .0156 & .0690 & .0966 \\
\hline & $(.0267)$ & $(.0206)$ & $(.0260)$ & $(.0309)$ & $(.0322)$ & $(.0349)$ \\
\hline
\end{tabular}

The estimates in the top panel are derived from Equations (1) and (2). Each selection parameter represents the magnitude of the log earnings premium associated with a given educational outcome which is due to selection based on cognitive or noncognitive ability measures from the NLSY (AFQT, mother's education, Rotter Scale, Rosenberg Self-Esteem Scale). The estimates in the bottom panel are derived by implementing the unobservable bounds procedure of Altonji et al. (2005) on the NLSY sample. Each parameter represents the proportion of the associated educational outcome's premium which is due to unobservable sorting if sorting based on observables and ounobservables is assumed to be equivalent. The standard errors for all selection parameters in each panel are obtained via bootstrap. 
Table 3

Estimated ACS Parameters

\begin{tabular}{|c|c|c|c|c|c|c|c|c|c|}
\hline \multicolumn{10}{|c|}{ Age Group } \\
\hline & $18-25$ & $26-30$ & $31-35$ & $36-40$ & $41-45$ & $46-50$ & $51-55$ & $56-60$ & $61-64$ \\
\hline$y^{H S}$ & 9.26 & 9.88 & 10.05 & 10.23 & 10.28 & 10.35 & 10.37 & 10.32 & 10.17 \\
\hline$\delta^{\text {SomeCol }}$ & .118 & .251 & .293 & .277 & .277 & .256 & .246 & .191 & .184 \\
\hline$\delta^{S T E M}$ & .507 & .818 & .895 & .875 & .876 & .894 & .837 & .769 & .692 \\
\hline$\delta^{\text {Business }}$ & .450 & .738 & .846 & .846 & .850 & .796 & .771 & .684 & .597 \\
\hline$\delta^{\text {Social }}$ & .133 & .545 & .710 & .748 & .755 & .664 & .629 & .543 & .467 \\
\hline$\delta^{\text {Arts\&Hum }}$ & -.022 & .294 & .439 & .503 & .550 & .494 & .399 & .429 & .324 \\
\hline$\beta_{\text {Age }}$ & 0.176 & 0.062 & 0.042 & 0.015 & 0.010 & -0.004 & -0.010 & -0.026 & -0.060 \\
\hline$\sigma_{H S}$ & 1.10 & 0.997 & 0.986 & 0.927 & 0.958 & 0.920 & 0.926 & 0.941 & 1.01 \\
\hline$\sigma_{\text {SomeCol }}$ & 0.998 & 0.895 & 0.897 & 0.877 & 0.892 & 0.924 & 0.914 & 0.984 & 1.07 \\
\hline$\sigma_{S T E M}$ & 0.966 & 0.729 & 0.697 & 0.748 & 0.802 & 0.801 & 0.849 & 0.938 & 1.16 \\
\hline$\sigma_{\text {Business }}$ & 0.938 & 0.752 & 0.820 & 0.827 & 0.865 & 0.960 & 0.925 & 0.968 & 1.13 \\
\hline$\sigma_{\text {Social }}$ & 1.03 & 0.868 & 0.890 & 0.856 & 0.901 & 0.975 & 1.00 & 1.04 & 1.18 \\
\hline$\sigma_{\text {Arts\&Hum }}$ & 1.03 & 0.905 & 0.905 & 0.971 & 0.983 & 0.991 & 1.03 & 1.03 & 1.20 \\
\hline
\end{tabular}

Each parameter is derived from Equation (5). The beta parameters represent the coefficients associated with each age group and educational outcome.

The sigma parameters represent the standard deviation of the low earnings residuals for each age group and educational outcome. 
Table 4

Average Simulated Lifetime Earnings

\begin{tabular}{ccccccc}
\hline \hline & High School & Some College & STEM & Business & Social Sciences & Arts/Humanities \\
\hline No selection correction & $1,513,893$ & $2,021,148$ & $3,706,155$ & $3,573,792$ & $3,240,067$ & $2,664,811$ \\
(1) with observable correction & $1,513,893$ & $1,810,602$ & $3,017,659$ & $2,899,500$ & $2,556,089$ & $2,195,055$ \\
(2) with discount factor $=.98$ & 918,653 & $1,090,592$ & $1,773,468$ & $1,710,515$ & $1,516,483$ & $1,297,775$ \\
(3) with tuition deducted & 918,653 & $1,050,992$ & $1,686,449$ & $1,622,625$ & $1,433,823$ & $1,209,222$ \\
\% of (4) below HS mean & .50 & .363 & .036 & .063 & .136 & .251 \\
\hline
\end{tabular}

Each value in the first four rows represents the median cumulative lifetime earnings as estimated from Equation (6) associated with each educational outcome given the assumptions listed in the first column. The results are obtained from a simulated sample of 100,000 individuals. All inputs to Equation (6) are obtained by estimating Equations (1)-(5) on the sample of men described in the data section who had any positive earnings over the past year. 
Table 5

Average Simulated Lifetime Earnings (Without Search Behavior)

\begin{tabular}{ccccccc}
\hline \hline & High School & Some College & STEM & Business & Social Sciences & Arts/Humanities \\
\hline No selection correction & $1,730,359$ & $2,253,274$ & $3,983,443$ & $3,858,248$ & $3,598,160$ & $3,049,220$ \\
(1) with observable correction & $1,730,359$ & $2,017,813$ & $3,245,244$ & $3,125,923$ & $2,836,080$ & $2,515,920$ \\
(2) with discount factor $=.98$ & $1,069,339$ & $1,220,342$ & $1,911,048$ & $1,843,933$ & $1,681,478$ & $1,484,313$ \\
(3) with tuition deducted & $1,069,339$ & $1,180,742$ & $1,821,099$ & $1,756,399$ & $1,593,663$ & $1,394,560$ \\
\% of $(4)$ below HS mean & .50 & .339 & .019 & .039 & .083 & .174 \\
\hline
\end{tabular}

Each value in the first four rows represents the median cumulative lifetime earnings as estimated from Equation (6) associated with each educational outcome given the assumptions listed in the first column. The results are obtained from a simulated sample of 100,000 individuals. All inputs to Equation (6) are obtained by estimating Equations (1)-(5) on the sample of men described in the data section who worked at least 50 weeks and at least 35 hours per week over the past year. 
Table 6

Average Simulated Lifetime Earnings

\begin{tabular}{ccccccc}
\hline \hline & High School & Some College & STEM & Business & Social Sciences & Arts/Humanities \\
\hline No selection correction & $1,513,893$ & $2,021,148$ & $3,706,155$ & $3,573,792$ & $3,240,067$ & $2,664,811$ \\
(1) with observable correction & $1,513,893$ & $1,810,602$ & $3,017,659$ & $2,899,500$ & $2,556,089$ & $2,195,055$ \\
(2) with selection correlation=.1 & $1,513,893$ & $1,806,967$ & $2,838,270$ & $2,759,038$ & $2,466,664$ & $2,163,006$ \\
(2) with selection correlation=.25 & $1,513,893$ & $1,801,848$ & $2,590,062$ & $2,559,836$ & $2,339,134$ & $2,115,105$ \\
(2) with selection correlation=.5 & $1,513,893$ & $1,793,696$ & $2,220,726$ & $2,261,465$ & $2,138,946$ & $2,038,664$ \\
(2) with selection correlation=.75 & $1,513,893$ & $1,785,395$ & $1,912,413$ & $2,000,340$ & $1,959,340$ & $1,965,790$ \\
(2) with selection correlation=.9 & $1,513,893$ & $1,780,493$ & $1,751,414$ & $1,859,281$ & $1,859,308$ & $1,925,635$ \\
(2) with selection correlation=1 & $1,513,893$ & $1,777,207$ & $1,649,439$ & $1,770,547$ & $1,795,590$ & $1,899,353$ \\
\hline
\end{tabular}

Each of the values in the last six rows represents the median cumulative lifetime earnings for each educational outcome under various assumptions regarding the degree of correlation between selection on observables and unobservables. These values are calculated using the unobservable bounding technique detailed in Altonji et al. (2005). 
Table 7

Average Simulated Lifetime Earnings (With Observable Selection Correction)

\begin{tabular}{ccccccc}
\hline \hline & High School & Some College & STEM & Business & Social Sciences & Arts/Humanities \\
\hline Bottom ability quintile & $1,362,586$ & $1,471,465$ & $2,222,052$ & $2,146,494$ & $1,938,842$ & $1,695,086$ \\
Second ability quintile & $1,487,935$ & $1,608,539$ & $2,435,700$ & $2,368,694$ & $2,103,224$ & $1,797,863$ \\
Third ability quintile & $1,642,030$ & $1,771,041$ & $2,625,187$ & $2,583,349$ & $2,355,509$ & $1,931,876$ \\
Fourth ability quintile & $1,814,696$ & $1,933,978$ & $2,917,298$ & $2,838,392$ & $2,586,506$ & $2,125,638$ \\
Highest ability quintile & $1,978,672$ & $2,136,913$ & $3,205,844$ & $3,071,049$ & $2,750,973$ & $2,394,728$ \\
\hline
\end{tabular}

Each value represents the median cumulative lifetime earnings as estimated from Equation (6) associated with each educational outcome given the assumptions listed in the first column. The results are obtained from a simulated sample of 100,000 individuals. All inputs to Equation (6) are obtained by estimating Equations (1)-(5) on the sample of men described in the data section who had any positive earnings over the past year. 